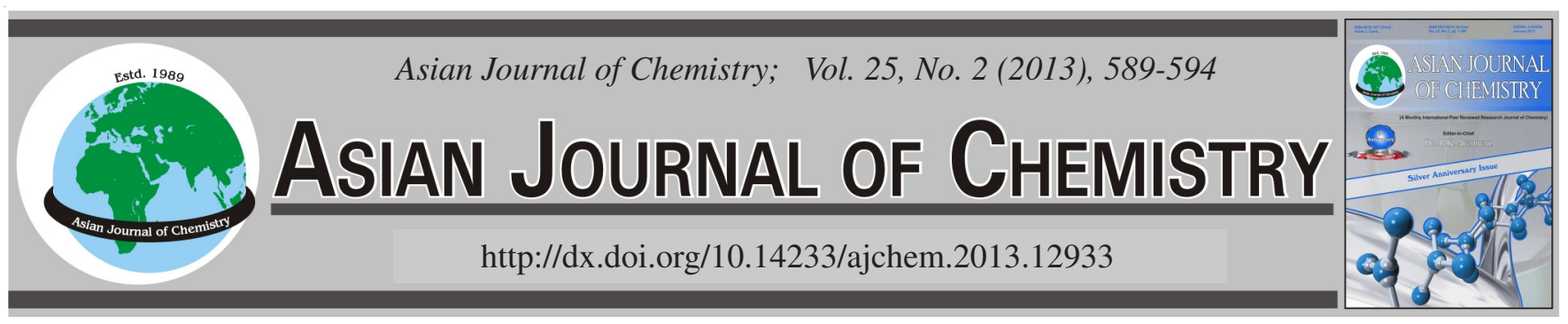

\title{
REVIEW
}

\section{Retention Mechanism Based on Linear Solvation Energy Relationships to RP-HPLC}

\author{
M. TIAN, B. TANG and K.H. Row*
}

Department of Chemical Engineering, Inha University, Incheon 402-751, South Korea

*Corresponding author: Fax: +82 32 8724046; Tel: +82 32 8607470; E-mail: rowkho@inha.ac.kr

\begin{abstract}
Linear solvation energy relationships (LSERs) have been used to correlate many complex chemical and biochemical properties with small sets of descriptors of molecular structure and chemistry. The interactions between solutes and solid sorbents are important factors. These interactions are governed by the nature and accessibility of the chemical sites at the material's surface. Characteristics, such as mobile phase modifiers and the type of stationary phase, have been established to detect the retention factors. The descriptors' properties can change as the environmental conditions varied. Comparing predicted and experimental retention factors suggests that the linear solvation energy relationships formalism is able to reproduce adequately the experimental retention factors of the solutes studied in different experimental conditions and evaluate retention characteristics.
\end{abstract}

Key Words: Linear solvation energy relationships, Reversed phase liquid chromatography, Chromatographic retention, Descriptors, Additives.

\section{INTRODUCTION}

Retention prediction and selectivity optimization are important to the development of reversed-phase liquid chromatography (RPLC) ${ }^{1}$. However, retention in RPLC is very complicated $^{2,3}$ and depends on many physical and chemical properties of the system, such as temperature $e^{4,5}$, the solute's molecular properties $^{6}$, the stationary phase ${ }^{7}$ and the composition of the mobile phase ${ }^{8}$. Many practical retention models ${ }^{9}$ for RP-HPLC, such as linear solvation energy relationships (LSER), have been developed and are widely used.

The most recent and widely accepted representation of the LSER model, as proposed by Abraham and Roses ${ }^{6}$, is given by:

$$
\log \mathrm{k}=\mathrm{c}+\mathrm{mV}_{\mathrm{x}}+\mathrm{s} \pi^{\mathrm{H}}+\mathrm{a} \Sigma \alpha_{2}^{\mathrm{H}}+\mathrm{b} \Sigma \beta_{2}^{0}+\mathrm{rR}_{2}
$$

in which $\log \mathrm{k}$ can be any free energy-related property where $\mathrm{k}$ is the retention factor, $\mathrm{V}_{\mathrm{x}}, \pi^{\mathrm{H}}, \Sigma \alpha_{2}{ }^{\mathrm{H}}, \Sigma \beta_{2}{ }^{0}$ and $\mathrm{R}_{2}$ denote solutedependent input parameters from scales related to the solute's polarizability, dipolarity (with some contribution from polarizability), hydrogen bond donating ability, hydrogen bond accepting ability and molecular size, respectively. m, s, a, b and $\mathrm{r}$ and the constant $\mathrm{c}$ are determined by multiparameter linear least squares regression analysis of data from solutes with known $\mathrm{V}_{\mathrm{x}}, \pi^{\mathrm{H}}, \Sigma \alpha_{2}{ }^{\mathrm{H}}, \Sigma \beta_{2}{ }^{0}$ and $\mathrm{R}_{2}$ values that span a reasonably wide range of interaction abilities ${ }^{10}$.

Intermolecular solute-solvent interactions have been reported to be important in not only separation science but also other areas of chemistry, such as syntheses, spectroscopy and pharmaceuticals ${ }^{11}$. This review focuses on theoretical research and applications of linear solvation energy relations in RP-HPLC.

\section{Theoretical researches}

Intermolecular interactions in chromatography: Retention and selectivity are important in chromatography and practical and theoretical research has always had to consider the chemical factors that affect these crucial parameters ${ }^{12}$. Resolution (R) is strongly dependent on these key factors:

$$
\mathrm{R}=\frac{\sqrt{\mathrm{N}}}{4} \frac{\alpha-1}{\alpha} \frac{\mathrm{k}^{\prime}}{1+\mathrm{k}^{\prime}}
$$

where $\alpha, \mathrm{k}$ and $\mathrm{N}$ are the conventional chromatographic selectivity, retention factor and number of theoretical plates, respectively ${ }^{13}$.

The capacity factor is the ratio of the retention volume $\left(V_{R}\right)$ corrected for the column dead volume $\left(V_{m}\right)$, determined by the column dead volume, as shown in eqn. 3 ,

$$
\mathrm{k}^{\prime}=\frac{\mathrm{V}_{\mathrm{R}}-\mathrm{V}_{\mathrm{m}}}{\mathrm{V}_{\mathrm{m}}}=\mathrm{k} \frac{\mathrm{V}_{\mathrm{s}}}{\mathrm{V}_{\mathrm{m}}}
$$

for pure partitioning process, the capacity factor can be related by fundamental thermodynamics to the phase transfer equilibrium constant, $\mathrm{K}$ and the ratio of the volume of stationary 
phase $\left(\mathrm{V}_{\mathrm{s}}\right)$ to the volume of mobile phase $\left(\mathrm{V}_{\mathrm{m}}\right)$ in a column. The equilibrium constant $\mathrm{K}$ (eqn. 4), enters into the general resolution equation in two ways.

$$
\mathrm{K}=\frac{[\text { solute }]_{\text {stationary }}}{[\text { solute }]_{\text {mobile }}}
$$

First, it enters explicitly through the selectivity factor, $\alpha$. It also affects the partition coefficient.

The partition coefficient arises from the interaction of the solute with molecules that constitute the mobile and stationary phases. Through fundamental thermodynamics it can be related to the free energy of the transfer of solute between the two phases.

$$
\Delta \mathrm{G}^{\mathrm{o}}=-\mathrm{RT} \ln \mathrm{K}
$$

The transfer free energy is related to how the solute molecules interact with the components of the mobile and stationary phases. As will be seen, solvatochromism allows the investigation of the chemical and physical processes by which a solute interacts with its surroundings. Solvatochromism studies often permit more direct experimental observation of these processes than does the measurement of thermodynamic parameters per $s e^{14}$.

Linear solvation energy relationships (LSER): The linear solvation energy relationship (LSER) is the established model for characterizing the quantitative structure-retention relationship (QSRR) and selectivity. Its fundamental conceptual definition, known as the solvatochromic model, was first introduced by Kamlet and Taft ${ }^{15-19}$. In their pioneering papers they showed that the chemical systems involve properties that are linearly related to the free reaction energy, the free transfer energy or the activation energy.

Properties such as the common logarithm of retention factor $(\log \mathrm{k})$ can be correlated to various fundamental molecular characteristics of the solvents and solutes involved in physicochemical processes ${ }^{20-23}$. The Kamlet-Taft solvatochromic model was initially employed by Chen et al. ${ }^{24}$ and Yang and Khaledi ${ }^{25}$. In eqn. $6, \log \mathrm{k}$ is correlated to known solute descriptors, $\mathrm{V}_{1}, \pi^{*}, \beta$ and $\alpha$ :

$$
\log \mathrm{k}=\mathrm{c}+\mathrm{mV}_{1}+\mathrm{s} \pi *+\mathrm{b} \beta+\mathrm{a} \alpha
$$

The first descriptor, $\mathrm{V}_{1}$ is the intrinsic volume of the solute and is usually divided by 100 to bring it to scale with the other terms. The solute polarity and polarizability are represented by the $\pi^{*}$ term. $\beta$ and $\alpha$ characterize the solute hydrogen bond accepting and donating abilities, respectively. The system coefficients (m, s, b and a) in eqn. 6 reflect differences in the two bulk phases, the aqueous and the stationary phases, between which the solute is transferring. They can be obtained by multivariable, simultaneous, linear regression ${ }^{26}$ and thus provide quantitative information about solute-solute, solutemobile phase and solute-stationary phase interactions. The intercept, c, provides information about the separation phase ratio $^{27} . \mathrm{m}$ is a measure of the relative susceptibility to cavity formation and general dispersion interactions of the solute with the stationary and the bulk aqueous phases, respectively. Differences of dipolarity/polarizability between the stationary and the bulk aqueous phases are represented by the coefficient s. $b$ and a represent the hydrogen bond donating and accepting abilities of the phase, respectively.
Another expression of LSER was introduced by Abraham et al $^{28,29}$. The solvation parameter model and is a revised form of the Kamlet-Taft solvatochromic model:

$$
\log \mathrm{k}=\mathrm{c}+\mathrm{mV}_{\mathrm{x}}+\mathrm{s} \pi^{\mathrm{H}}+\mathrm{a} \Sigma \alpha_{2}^{\mathrm{H}}+\mathrm{b} \Sigma \beta_{2}^{0}+\mathrm{rR}_{2}
$$

where, $\mathrm{V}_{\mathrm{x}}$ represents the McGowan solute characteristic volume $^{30}$ and $R_{2}$ represents the excess molar refraction of the solute. The subscript 2 denotes that these parameters are solute properties. The coefficients $\mathrm{m}, \mathrm{a}$ and $\mathrm{b}$ are the same as in eqn. 6 .

It is important to note that the Kamlet-Taft solvatochromic model (eqn. 6) does not contain the excess molar refraction solute descriptor, $\mathrm{R}_{2}$. In addition, the solvatochromic model uses the intrinsic volume $\left(\mathrm{V}_{1}\right)$ of the solute instead of the McGowan characteristic volume $\left(\mathrm{V}_{\mathrm{x}}\right)$. While exact quantitative agreement cannot be expected, discrepancies in overall trends predicted by both approaches are rare.

\section{Application of linear solvation energy relations to corre- lating retention in RP-HPLC}

Solute parameters: Linear solvation energy relations are designed to probe the type and relative importance of the interactions governing solute retention. More important, the physico-chemical basis of the solute parameters is the key to understanding the intermolecular interactions governing the various phases ${ }^{31-33}$.

Linear solvation energy relation analysis was applied to reversed phase data obtained by Tan et al. ${ }^{34}$ reported on a set of aliphatic, halogenated and aromatic solutes ${ }^{34}$. Some conventional solutes and their parameters are given in Table-1, including aliphatic and aromatic alcohols, aldehydes, amides, esters, ethers, ketones, nitriles, nitro and halogenated compounds, alkylbenzenes, phenols and polyaromatic hydrocarbons. The solute set was not unduly loaded with low polarity solutes whose retentions are easily correlated with their size. Nor is it loaded with congeners which differ only slightly in their physico-chemical properties.

Recommendations for selecting appropriate solutes have been gathered from a survey of the literature: (1) mathematically, a minimum number of seven solutes are needed to solve a multiple linear regression equation for six unknowns; (2) there should be an absence of significant cross correlation among the descriptors and clustering of specific descriptors should be avoided; (3) since UV absorption is used, the solutes should have absorbances between 200 and $250 \mathrm{~nm}$, for convenient detection and (4) solutes should be stable in the employed solutions

In all the mobile phases investigated, the coefficient of $\Sigma \beta_{2}{ }^{0}$ (b) and most of the coefficients of $\pi^{\mathrm{H}}$ (s) were negative, implying that an increase in hydrogen bond (HB) basicity and solute dipolarity/polarizability decreases the overall retention of the molecule. The positive coefficients of $\mathrm{V}_{\mathrm{x}}, \Sigma \alpha_{2}{ }^{\mathrm{H}}$ and $\mathrm{R}_{2}$ ( $\mathrm{m}$, a and $\mathrm{r}$, respectively) indicated high solute volume and high excess molar refractivity of hydrogen bond acidity in the solute volume. The magnitude of the coefficients, excess molar refractivity and solute dipolarity/polarizability generally play the largest role in determining the retention of solutes in all mobile phases' studied ${ }^{35}$.

If a solute had a value of $\mathrm{R}_{2}$ of zero, it would not occupy any space in the solvent and would require no endoergic cavity 
TABLE-1

THE SOLUTES WITH DIFFERENT FUNCTIONAL GROUPS AND THEIR DESCRIPTORS FOR THE SALVATION PARAMETER MODEL

\begin{tabular}{|c|c|c|c|c|c|c|}
\hline \multicolumn{2}{|l|}{ No } & Solute & \multirow{2}{*}{$\frac{V_{X} / 100}{0.7309}$} & \multirow{2}{*}{$\frac{\left(\pi_{2}\right)^{\mathrm{H}}}{0.42}$} & \multirow{2}{*}{$\frac{\left(\alpha_{2}\right)^{\mathrm{H}}}{0.37}$} & \multirow{2}{*}{$\frac{\left(\beta_{2}\right)^{\mathrm{H}}}{0.48}$} \\
\hline & 1 & Butanol & & & & \\
\hline & 2 & 1-Hexanol & 1.0127 & 0.38 & 0.37 & 0.48 \\
\hline I. Hydroxyl group & 3 & 1-Octanol & 1.2945 & 0.34 & 0.37 & 0.48 \\
\hline & 4 & 2-Propanol & 0.5900 & 0.36 & 0.33 & 0.56 \\
\hline & 5 & Cyclohexanol & 0.9041 & 0.54 & 0.30 & 0.57 \\
\hline \multirow{21}{*}{$\begin{array}{l}\text { II. Carbonyl } \\
\text { group }\end{array}$} & 6 & 1-Butanal & 0.6879 & 0.65 & 0 & 0.45 \\
\hline & 7 & 1-Hexanal & 0.9679 & 0.63 & 0 & 0.45 \\
\hline & 8 & 1-Heptanal & 1.1106 & 0.61 & 0 & 0.45 \\
\hline & 9 & 1-Octanal & 1.2515 & 0.59 & 0 & 0.45 \\
\hline & 10 & $\mathrm{~N}, \mathrm{~N}$-Dimethyl formamide & 0.6468 & 1.31 & 0 & 0.74 \\
\hline & 11 & N,N-Diethyl formamide & 0.9286 & 1.25 & 0 & 0.76 \\
\hline & 12 & N,N-Dibutyl formamide & 1.4922 & 1.19 & 0 & 0.80 \\
\hline & 13 & N,N-Dimethyl acetamide & 0.7877 & 1.33 & 0 & 0.78 \\
\hline & 14 & N,N-Diethyl acetamide & 1.0695 & 1.30 & 0 & 0.78 \\
\hline & 15 & $n$-Propyl formate & 0.7466 & 0.63 & 0 & 0.38 \\
\hline & 16 & $n$-Butyl acetate & 1.0284 & 0.60 & 0 & 0.45 \\
\hline & 17 & $n$-Amyl acetate & 1.1693 & 0.58 & 0 & 0.45 \\
\hline & 18 & $n$-Hexyl acetate & 1.3102 & 0.56 & 0 & 0.45 \\
\hline & 19 & Ethyl propionate & 0.8875 & 0.58 & 0 & 0.45 \\
\hline & 20 & Ethyl butyrate & 1.0284 & 0.58 & 0 & 0.45 \\
\hline & 21 & Acetone & 0.5407 & 0.70 & 0.04 & 0.49 \\
\hline & 22 & 2-Butanone & 0.6879 & 0.70 & 0 & 0.51 \\
\hline & 23 & 2-Hexanone & 0.9697 & 0.68 & 0 & 0.51 \\
\hline & 24 & 2-Heptanone & 1.1106 & 0.66 & 0 & 0.51 \\
\hline & 25 & 2-Nonanone & 1.3924 & 0.62 & 0 & 0.51 \\
\hline & 26 & Cyclopentanone & 0.7202 & 0.86 & 0 & 0.52 \\
\hline \multirow{4}{*}{ III. Ether group } & 27 & Ethyl ether & 0.7309 & 0.25 & 0 & 0.45 \\
\hline & 28 & n-Propyl ether & 1.0127 & 0.23 & 0 & 0.45 \\
\hline & 29 & n-Butyl ether & 1.2945 & 0.21 & 0 & 0.45 \\
\hline & 30 & Dioxane & 0.6810 & 0.75 & 0 & 0.64 \\
\hline \multirow{6}{*}{ IV. Cyanogroup } & 31 & $n$-Propionitrile & 0.5451 & 0.90 & 0.02 & 0.36 \\
\hline & 32 & $n$-Valeronitrile & 0.8269 & 0.90 & 0 & 0.36 \\
\hline & 33 & $n$-Hexanitrile & 0.9678 & 0.88 & 0 & 0.36 \\
\hline & 34 & $n$-Hexyl cyanide & 1.1087 & 0.86 & 0 & 0.36 \\
\hline & 35 & $n$-Heptyl cyanide & 1.2496 & 0.84 & 0 & 0.36 \\
\hline & 36 & $n$-Octyl cyanide & 1.3905 & 0.82 & 0 & 0.36 \\
\hline \multirow{6}{*}{ V. Alkyl } & 37 & $n$-Nitropropane & 0.7055 & 0.95 & 0 & 0.31 \\
\hline & 38 & $n$-Nitrobutane & 0.8464 & 0.93 & 0 & 0.31 \\
\hline & 39 & $n$-Nitropentane & 0.9873 & 0.91 & 0 & 0.31 \\
\hline & 40 & Methylene chloride & 0.4943 & 0.57 & 0.10 & 0.05 \\
\hline & 41 & Chloroform & 0.6167 & 0.49 & 0.15 & 0.02 \\
\hline & 42 & Dibromomethane & 0.5995 & 0.67 & 0.10 & 0.10 \\
\hline \multirow{22}{*}{ VI. Phenyl } & 43 & Benzylalcohol & 0.9160 & 0.87 & 0.33 & 0.56 \\
\hline & 44 & 2-Phenyl ethanol & 1.0569 & 0.91 & 0.30 & 0.64 \\
\hline & 45 & 2-Phenyl ethanol & 1.1978 & 0.90 & 0.30 & 0.67 \\
\hline & 46 & Benzaldehyde & 0.8730 & 1.00 & 0 & 0.39 \\
\hline & 47 & N-Benzyl formamide & 1.1137 & 1.80 & 0.40 & 0.63 \\
\hline & 48 & Methyl benzoate & 1.0726 & 0.85 & 0 & 0.46 \\
\hline & 49 & Ethyl benzoate & 1.2135 & 0.85 & 0 & 0.46 \\
\hline & 50 & Anisole & 0.9160 & 0.75 & 0 & 0.29 \\
\hline & 51 & Acetophenone & 1.0139 & 1.01 & 0 & 0.48 \\
\hline & 52 & Propiophenone & 1.1548 & 0.95 & 0 & 0.51 \\
\hline & 53 & Benzophenone & 1.4808 & 1.50 & 0 & 0.50 \\
\hline & 54 & Benzonitrile & 0.8711 & 1.11 & 0 & 0.33 \\
\hline & 55 & $m$-Toluenitrile & 1.0120 & 1.11 & 0 & 0.34 \\
\hline & 56 & $m$-Toluenitrile & 1.0120 & 1.15 & 0 & 0.45 \\
\hline & 57 & Nitrobenzene & 0.8906 & 1.11 & 0 & 0.28 \\
\hline & 58 & $m$-Nitrotoluene & 1.0315 & 1.10 & 0 & 0.25 \\
\hline & 59 & $o$-Nitrotoluene & 1.0315 & 1.11 & 0 & 0.27 \\
\hline & 60 & $p$-Nitrotoluene & 1.0315 & 1.11 & 0 & 0.28 \\
\hline & 61 & $p$-Nitrobenzyl & 1.2065 & 1.50 & 0 & 0.40 \\
\hline & 62 & $p$-Nitrobenzyl & 1.1539 & 1.34 & 0 & 0.40 \\
\hline & 63 & Fluorobenzene & 0.7341 & 0.57 & 0 & 0.10 \\
\hline & 64 & Chlorobenzene & 0.8388 & 0.65 & 0 & 0.07 \\
\hline
\end{tabular}




\begin{tabular}{|c|c|c|c|c|c|c|}
\hline & 65 & Bromobenzene & 0.8914 & 0.73 & 0 & 0.09 \\
\hline & 66 & Iodobenzene & 0.9746 & 0.82 & 0 & 0.12 \\
\hline & 67 & Benzyl bromide & 1.0323 & 0.98 & 0 & 0.20 \\
\hline & 68 & $p$-Chlorotoluene & 0.9797 & 0.67 & 0 & 0.07 \\
\hline & 69 & $p$-Bromotoluene & 1.0323 & 0.74 & 0 & 0.09 \\
\hline & 70 & p-Dichlorobenzene & 0.9612 & 0.75 & 0 & 0.02 \\
\hline & 71 & Benzene & 0.7164 & 0.52 & 0 & 0.14 \\
\hline & 72 & Toluene & 0.8573 & 0.52 & 0 & 0.14 \\
\hline & 73 & Ethylbenzene & 0.9982 & 0.51 & 0 & 0.15 \\
\hline & 74 & $n$-Propylbenzene & 1.1391 & 0.50 & 0 & 0.15 \\
\hline & 75 & $n$-Butylbenzene & 1.2800 & 0.51 & 0 & 0.15 \\
\hline & 76 & tert-Butylbenzene & 1.2800 & 0.49 & 0 & 0.16 \\
\hline & 77 & $p$-Xylene & 0.9982 & 0.52 & 0 & 0.16 \\
\hline & 78 & Mesitylene & 1.1391 & 0.52 & 0 & 0.19 \\
\hline & 79 & Biphenyl & 1.3242 & 0.99 & 0 & 0.22 \\
\hline & 80 & Naphthalene & 1.0854 & 0.92 & 0 & 0.20 \\
\hline & 81 & Anthracene & 1.4544 & 1.34 & 0 & 0.26 \\
\hline & 82 & Phenol & 0.7751 & 0.89 & 0.60 & 0.30 \\
\hline & 83 & $m$-Cresol & 0.9160 & 0.88 & 0.57 & 0.34 \\
\hline & 84 & $p$-Cresol & 0.9160 & 0.87 & 0.57 & 0.31 \\
\hline & 85 & $o$-Cresol & 0.9160 & 0.86 & 0.52 & 0.30 \\
\hline & 86 & $p$-Ethylphenol & 1.0569 & 0.90 & 0.55 & 0.36 \\
\hline & 87 & $p$-Chlorophenol & 0.8975 & 1.08 & 0.67 & 0.20 \\
\hline & 88 & Methylparaben & 0.9000 & 1.37 & 0.69 & 0.34 \\
\hline VII Heterocycle & 89 & Caffeine & 1.500 & 1.60 & 0 & 1.35 \\
\hline vil. Heterocycie & 90 & Pyridine & 0.6310 & 0.84 & 0 & 0.52 \\
\hline
\end{tabular}

formation to hold it. Nor would a solute of no size, hence one with no electrons, be able to enter into any dispersive processes. In a series of increasingly sized solutes with the same $\mathrm{pH}$, $\Sigma \alpha_{2}{ }^{\mathrm{H}}$ and $\Sigma \beta_{2}{ }^{0}$, cavity formation would increase linearly with solute size, as would the dispersive interactions. Any two processes with the same values of the $r$ coefficient would show the same tendency of log $k$ with the same changes of solute size ${ }^{36}$.

According to Tian and Row ${ }^{37}$, positive ' $\mathrm{m}$ ' values indicate that retention increases with increasing solute size. Furthermore, a small negative $m$ value shows that the endoergic cavity formation term does not have the most important effect on retention. The difference in dipolarity/polarizability is represented by the coefficient ' $\mathrm{s}$ '. If this coefficient is negative, the solutes experience a microenvironment that has less dipolar/ polarizable characteristics than the aqueous phase. The coefficient ' $a$ ' is important in the solvatochromic model of the two systems studied here, as it represents the difference between the HB accepting basicity of the mobile phase additives and that of the aqueous phase. The coefficient $b$ is the second most important factor in the LSER solvation parameter model. It is proportional to the difference between the hydrogen bond donating abilities of the mobile phase additives and the aqueous phase. Comparing the coefficients for each concentration of additives shows that $r$ has the largest absolute value of all the coefficients for all the concentrations studied here. As discussed in an earlier study ${ }^{38}$, the coefficient ' $r$ ' represents the excess molar refraction of the solute.

Mobile phase additives: The linear solvation energy relationship model has been studied as a tool for estimating the partitioning and sorption coefficients of organic compounds in different mobile phases ${ }^{39-43}$. Linear solvation energy relationships have been used extensively to examine retention mechanisms in reversed phase liquid chromatography ${ }^{44,45}$. The composition of the mobile phase is an important factor affecting analytes' retention times. Ionic liquids, sodium lauryl sulfate (SDS), cetyltrimethylammonium bromide (CTAB), organic acids and inorganic salts have been shown capable of being used as mobile phase additives in RP-HPLC when mixed with other solvents.

Linear solvation energy relationships can provide valuable insights into the chemical and physical factors controlling retention in RPLC, with many studies using it to characterize mobile phase modifier effects. Many of these are listed in Table- 2 along with the stationary phases, solutes and mobile phases used in each study.

In Tian's works ${ }^{37,46}$, several micellar liquid chromatography (MLC) systems using cationic surfactants 'c' (CTAB and SDS) and a mixture of water with (methanol, $n$-propanol and $n$-butanol) modifiers were characterized using the linear solvation energy relationship solvation parameter model. The linear solvation energy relationship model predicted retention factors well with high squared correlation coefficients $\left(\mathrm{r}^{2}>\right.$ 0.99). $\mathrm{Han}^{47}$ used two phosphates $\left(\mathrm{NaH}_{2} \mathrm{PO}_{4}\right.$ and $\left.\mathrm{Na}_{2} \mathrm{HPO}_{4}\right)$ as mobile phase additives in the linear solvation energy relationship model to investigate the fundamental chemical interactions governing the retentions of 7 aromatic compounds. The results demonstrated the model's capability to predict retention factors with very high correlation coefficients $\left(\mathrm{r}^{2}>0.99\right.$ for $\mathrm{NaH}_{2} \mathrm{PO}_{4}$ and $\mathrm{r}^{2}>0.96$ for $\mathrm{Na}_{2} \mathrm{HPO}_{4}$ ). Blackwell and Corr ${ }^{48}$ compared the effects of trifluoroacetic acid, triethylamine and a combination of both on linear solvation energy relationships with those observed in the absence of additives. Wang et al. ${ }^{1,49}$, Tian et al. ${ }^{50}$ and Zhu et al. ${ }^{51}$ used different ionic liquids as mobile phase additives to investigate the effects of a series of organic compounds on retention factor via the linear solvation energy relationship model. Comparing predicted and experimental results showed that the linear solvation energy relationship model could reproduce experimental retention factors of the solutes under different mobile phase conditions. It is also useful for modeling the interactions of the solutes between the 


\begin{tabular}{|c|c|c|c|}
\hline \multicolumn{4}{|c|}{$\begin{array}{c}\text { TABLE-2 } \\
\text { LSER CHARACTERIZATION OF RPLC SYSTEMS }\end{array}$} \\
\hline Solutes & Column & $\begin{array}{l}\text { Mobile phase } \\
\end{array}$ & Reference \\
\hline 8 aromatic compounds & & $\begin{array}{l}\text { CTAB and a mixture of water with methanol, } n \text { - } \\
\text { propanol and } n \text {-butanol }\end{array}$ & 47 \\
\hline 9 aromatic compounds & & $\begin{array}{l}\text { SDS }(0.03-0.09 \mathrm{M}) \text { and ionic liquids }(0.003-0.009 \mathrm{M}) \\
\text { as modifiers in acetonitrile/water }(5-20 \%)\end{array}$ & 1 \\
\hline 10 aromatic compounds & $\mathrm{C}_{18}$ & $\begin{array}{l}\text { SDS and a mixture of water with methanol, } n \text {-propanol } \\
\text { and } n \text {-butyl alcohol as modifiers }\end{array}$ & 37 \\
\hline 10 aromatic compounds & & Ionic liquid modifiers & 51 \\
\hline 9 aromatic compounds & & Ionic liquids with $5-20 \%$ acetonitrile in water & 50 \\
\hline 9 organic compounds & & Ionic liquid and methanol (65-80\%) & 52 \\
\hline 7 aromatic compounds & & $\mathrm{NaH}_{2} \mathrm{PO}_{4}, \mathrm{Na}_{2} \mathrm{HPO}_{4}$ and acetonitrile & 48 \\
\hline 22 aromatic compounds & $\mathrm{C}_{8}$ & $\begin{array}{l}\text { SDS and CTAB with } 0-10 \% \text { methanol, } n \text {-propanol } \\
\text { and } n \text {-butanol as mobile phase modifiers }\end{array}$ & 46 \\
\hline 20 organic compounds & 5 different columns & $\begin{array}{l}\text { Trifluoroacetic acid, triethylamine and a combination } \\
\text { of trifluoroacetic acid and triethylamine }\end{array}$ & 49 \\
\hline $\begin{array}{l}87 \text { compounds (aromatic and } \\
\text { aliphatic) }\end{array}$ & $\begin{array}{c}\text { One } \mathrm{C}_{18} \text { column and two } \mathrm{C}_{8} \text { columns } \\
\text { with varying silanol activity }\end{array}$ & Acetonitrile/water (50:50) & 34 \\
\hline 61 compounds & Zorbax- $\mathrm{C}_{8}$ & Methanol, acetonitrile, trifluoroacetic acid & 36 \\
\hline 32 compounds & Butylimidazolium-based column & Methanol/water & 12 \\
\hline 22 compounds & 5 columns & Methanol, acetonitrile, trifluoroacetic acid & 32 \\
\hline 32 compounds & 19 columns with different types & Acetonitrile/water (30:70) & 31 \\
\hline
\end{tabular}

stationary and mobile phases and evaluating the retention characteristics of HPLC.

The modifier can greatly affect the intermolecular interactions governing retention. Some polar solvents that are commonly used as mobile phase modifiers in RPLC, such as methanol $\left(\pi^{\mathrm{H}}=0.6\right)$, acetonitrile $\left(\pi^{\mathrm{H}}=0.75\right)$ and tetrahydrofuran $(\mathrm{pH}=0.58)$, have very different hydrogen bonding properties. For example, the HB acidities $\left(\Sigma \alpha_{2}{ }^{\mathrm{H}}\right)$ of methanol and acetonitrile are 0.93 and 0.19 , respectively. Their basicities are also different $\left(\Sigma \beta_{2}{ }^{0}\right.$ methanol $=0.63, \Sigma \beta_{2}{ }^{0}$ acetonitrile $=$ $0.31)$. These differences suggest that the mobile phase modifiers will lead to significant differences in chromatographic selectivity. This is consistent with reported results and so validates the solvatochromic solvent scales upon which LSERs are ultimately based.

\section{Conclusion}

This article briefly reviews the role of linear solvation energy relationship in RP-HPLC. Linear solvation energy relationship is a powerful and robust approach for analyzing solute interactions in the mobile and stationary phases of RP-HPLC, even when applied to chemically diverse data sets. Linear solvation energy relationships application was outlined in terms of solute descriptors and mobile phase additives. It is still easier to measure retention than to measure the relevant parameters and predict retention; though linear solvation energy relationship has made progress by allowing the separation of not only polar and non-polar interactions but also the separation of polar interactions into a sum of a number of separate interactions. There is much to be hoped for from quantum mechanics as to how such parameters can be constructed, but there has been too little collaboration in this area between theoreticians, experimental chemists and separation scientists.

\section{ACKNOWLEDGEMENTS}

This research was a part of the project titled "Korea Sea Grant Program (Gyeong-gi Sea Grant)" funded by the Ministry of Land, Transport and Maritime Affairs, Korea

\section{REFERENCES}

1. Y. Wang, M. Tian and K.H. Row, J. Liq. Chromatogr. Rel. Technol., 33, 202 (2010).

2. C. Horváth, W. Melander and I. Molnár, J. Chromatogr. A, 125, 129 (1976).

3. P.W. Carr, L.C. Tan and J.H. Park, J. Chromatogr. A, 724, 1 (1996).

4. P.W. Carr, R.M. Doherty, M.J. Kamlet, R.W. Taft, W. Melander and C. Horvath, Anal. Chem., 58, 2674 (1986).

5. I.W. Li and P.W. Carr, Anal. Chem., 69, 2202 (1997).

6. M.H. Abraham and M. Rosés, J. Phys. Org. Chem., 7, 672 (1994).

7. L.C. Tan and P.W. Carr, J. Chromatogr. A, 799, 1 (1998).

8. K. Valko, L.R. Snyder and J.L. Glajch, J. Chromatogr. A, 656, 501 (1993).

9. C.H. Lochmüller, R. Charles, J.A. Allison and J.B. Steven, J. Chromatogr. A, 656, 3 (1993).

10. M. Vitha and P.W. Carr, J. Chromatogr. A, 1126, 143 (2006).

11. A.H. Lowrey, C.J. Cramer, J.J. Urban and G.R. Famini, Computers Chem., 19, 209 (1995).

12. P.R. Fields, Y. Sun and A.M. Stalcup, J. Chromatogr. A, 1218, 467 (2011).

13. B.L. Karger, L.R. Snyder and C. Horvath, An Introduction to Separation Science, Wiley, New York (1972).

14. P.W. Carr, Microchem. J., 48, 4 (1993).

15. M.J. Kamlet and R.W. Taft, J. Am. Chem. Soc., 98, 377 (1976).

16. M.J. Kamlet and R.W. Taft, J. Am. Chem. Soc., 98, 2886 (1976).

17. M.J. Kamlet, J.L. Abboud and R.W. Taft, J. Am. Chem. Soc., 99, 6027 (1977).

18. M.J. Kamlet, J.L. Abboud and R.W. Taft, J. Org. Chem., 48, 2877 (1983).

19. M.J. Kamlet, R.M. Doherty, M.H. Abraham, Y. Marcus and R.W. Taft, J. Phys. Chem., 92, 5244 (1988).

20. J. Zheng, S.K. Han and K.H. Row, Bull. Korean Chem. Soc., 26, 629 (2005).

21. Y. Polyakova, L.M. Jin and K.H. Row, J. Liq. Chromatogr. Rel. Technol., 29, 533 (2006).

22. J. Zheng, Y. Polyakova and K.H. Row, Chromatographia, 64, 129 (2006).

23. Y. Polyakova, L.M. Jin and K.H. Row, Bull. Korean Chem. Soc., 27, 211 (2006).

24. N. Chen, Y. Zhang, S. Terabe and T. Nakagawa, J. Chromatogr., 678, 327 (1994).

25. S. Yang and M.G. Khaledi, Anal. Chem., 67, 499 (1995).

26. P.W. Carr, R.M. Doherty, M.J. Kamlet, R.W. Taft, W. Malender and C. Horvath, Anal. Chem., 58, 2674 (1986).

27. P.W. Carr, Microchem. J., 48, 4 (1993).

28. M.H. Abraham, G.S. Whiting, R.M. Doherty and W.J. Shuely, J. Chem. Soc., Perkin Trans. II, 1451 (1990).

29. M.H. Abraham, H.S. Chadha, G.S. Whiting and R.C. Mitchell, J. Pharm. Sci., 83, 1085 (1994). 
30. M.H. Abraham and J.C. McGowan, Chromatographia, 23, 243 (1987).

31. L. Szepesy, J. Sep. Sci., 26, 201 (2003).

32. A. Wang and P.W. Carr, J. Chromatogr. A, 965, 3 (2002).

33. Y.B. He, J.J. Zhu, L.S. Wang and Z. Zhang, Bull. Environ. Contam. Toxicol., 55, 635 (1995).

34. L.C. Tan, P.W. Carr and M.H. Abraham, J. Chromatogr. A, 752, 1 (1996).

35. P. Burg, M.H. Abraham and D. Cagniant, Carbon, 41, 867 (2003).

36. A. Wang, L.C. Tan and P.W. Carr, J. Chromatogr. A, 848, 21 (1999).

37. M. Tian and K.H. Row, J. Liq. Chromatogr. Rel. Technol., 32, 772 (2009)

38. M.A. Garcia, M.F. Vitha and M.L. Marina, J. Liq. Chromatogr. Rel. Technol., 23, 873 (2000)

39. S. Endo and T.C. Schmidt, Fluid Phase Equilib., 246, 143 (2006).

40. M.A. García, M.F. Vitha, J. Sandquist, K. Mulville and M.L. Marina, J. Chromatogr. A, 918, 1 (2001).

41. H. Bui, T. Perun, T. Masquelin, T. Castle, J. Dage and M.S. Kuo, J. Chromatogr. A, 1206, 186 (2008).
42. M. Vitha and P.W. Carr, J. Chromatogr. A, 1126, 143 (2006).

43. J.L. Yeatts, R.E. Baynes, X.R. Xia and J.E. Riviere, J. Chromatogr. A, 1188, 108 (2008).

44. Y. Sun, B. Cabovska, C.E. Evans, T.H. Ridgway and A.M. Stalcup, Anal. Bioanal. Chem., 382, 728 (2005).

45. D.S. Van Meter, Y. Sun, K.M. Parker and A.M. Stalcup, Anal. Bioanal. Chem., 390, 897 (2008).

46. M. Tian and K.H. Row, Bull. Korean Chem. Soc., 29, 979 (2008).

47. D. Han and K.H. Row, Asian J. Chem., 22, 2717 (2010).

48. J.A. Blackwell and P.W. Carr, J. High Resolut. Chromatogr., 21, 427 (1998).

49. Y. Wang, D. Han, M. Tian and K.H. Row, Korean J. Chem. Eng., 26, 812 (2009).

50. M. Tian and K.H. Row, Chem. Res. Chin. Univ., 25, 306 (2009).

51. T. Zhu, M. Tian and K.H. Row, Chem. Res. Chin. Univ., 26, 532 (2010). 